\title{
Geografias do dissenso: sobre conflitos, justiça ambiental e cartografia social no Brasil
}

Geographies of divergence: about conflicts, environmental justice and social cartography in Brazil

Géographies de la divergence : à propos de conflits, de justice environnementale et de cartographie sociale au Brésil

\section{Marco Antonio Sampaio Malagodi}

\section{(2) OpenEdition}

\section{Journals}

Edição electrónica

URL: http://journals.openedition.org/espacoeconomia/136

DOI: 10.4000/espacoeconomia.136

ISSN: 2317-7837

Editora

Núcleo de Pesquisa Espaço \& Economia

Refêrencia eletrónica

Marco Antonio Sampaio Malagodi, « Geografias do dissenso: sobre conflitos, justiça ambiental e cartografia social no Brasil », Espaço e Economia [Online], 1 | 2012, posto online no dia 09 março 2013, consultado o 01 maio 2019. URL : http://journals.openedition.org/espacoeconomia/136 ; DOI : 10.4000/espacoeconomia.136

Este documento foi criado de forma automática no dia 1 Maio 2019

(C) NUPEE 


\section{Geografias do dissenso: sobre conflitos, justiça ambiental e cartografia social no Brasil}

Geographies of divergence: about conflicts, environmental justice and social cartography in Brazil

Géographies de la divergence : à propos de conflits, de justice environnementale et de cartographie sociale au Brésil

\section{Marco Antonio Sampaio Malagodi}

\section{Introdução: Por que uma geografia do dissenso?}

1 Henri Acselrad (2005) utiliza a expressão geografia do dissenso para representar a dinâmica dos conflitos ambientais gerada no Estado do Rio de Janeiro no contexto da recente busca de recuperação do crescimento econômico a qualquer custo, quando investiu-se contra a responsabilidade ambiental do Estado e se opôs de forma direta agentes econômicos e "atores sociais no terreno", como diz. Representaria, assim, uma "geografia da crítica que a sociedade civil (...) endereça à configuração espacial do modelo de desenvolvimento econômico instaurado no estado" (ACSELRAD, 2005, p.8). Esta dinâmica conflitual, diz o autor, pode nos ajudar a compreender as ações de resistência que vêm contestando o modo como o desenvolvimento se foi configurando espacialmente no estado. Entre essas ações estão aquelas que se confrontam com as "dinâmicas locacionais que têm penalizado os grupos sociais que pouco puderam se fazer ouvir nas esferas decisórias” (idem).

Como ilustração atual, podemos ver uma face dessa dinâmica no Norte Fluminense a partir do processo de implantação do complexo de mega-empreendimentos no contexto do Porto do Açu, proposta que, segundo Soffiati Netto (SOFFIATI NETO, 2011) já havia sido rejeitada anteriormente no estado de Santa Catarina em função da avaliação de seus impactos socioambientais negativos. No dia dois de setembro deste ano, participamos de 
uma audiência pública realizada em Campos dos Goytacazes (RJ), referente ao processo de licenciamento do novo Distrito Industrial de São João da Barra (RJ), empreendimento integrado ao contexto do também chamado "Super Porto do Açu", realização do grupo EBX, comandado pelo empresário Eike Batista. Sob uma atmosfera de tensão gerada pela: (i) polêmica estratégia de licenciamento; (ii) pelos atuais mecanismos de desapropriação de agricultores do Quinto Distrito de São João da Barra; e (iii) pela da própria precariedade do mecanismo de esclarecimento e controle público através das audiências públicas, alguns manifestantes expressaram sua indignação. Entre eles estavam agricultores familiares e ambientalistas, que denunciaram a existência de um continuum entre as agendas da empresa e dos -- supostamente controladores/fiscalizadores -órgãos governamentais, ambas voltadas para a aprovação de tais empreendimentos. Requentando antigas fórmulas, o desenvolvimento (cuja retórica evita a adjetivação "capitalista"), naturalizado e entendido em si mesmo como a realização do bem-comum, continua sendo o carro-chefe da operação simbólica que disputa o status de escolha social mais legítima frente a tantos outros projetos de sociedade:

"Existem aqueles que não gostam, que não querem sair das suas casas, das suas terras, pelo valor afetivo... e a gente respeita isso. Mas, em contrapartida, nós, como representantes desta terra, a gente vê essa... como uma grande oportunidade de desenvolvimento, com o crescimento do cidadão, com geração de renda, com distribuição de riqueza." (REPORTAGEM INTER TV/REDE GLOBO, 2011a).

3 Contrapondo-se a esta fala da prefeita de São João da Barra, podemos citar a de uma agricultora, moradora do Quinto Distrito:

"A gente vai permanecer na terra... a gente tem uma vida digna e honesta aqui, trabalhamos pra sobreviver daqui, da terra. Isso aqui tem documentos... é tudo em dia... Então, a gente não tem como temer... a gente confia em Deus, e vamos torcer pra continuar lutando e trabalhando a nossa terra". (REPORTAGEM INTER TV/REDE GLOBO, 2011b).

4 Como em outras dinâmicas de configuração espacial do desenvolvimento de precário teor democrático, e mais especificamente no contexto dos conflitos ambientais, os direitos de uma suposta minoria são suspensos ou precarizados em nome da geração de emprego e renda para uma suposta maioria. Novamente se vê a retórica de um necessário sacrifício social "de alguns" para a realização do interesse comum "de todos", deslegitimando tantas outras formas de existência social, tantos modos diferenciados de apropriação, uso e significação do território. Uma tentativa mesmo de invisibilização de tais atores sociais, associada à idéia de um "vazio demográfico" e político, e à ação concreta de desvalorização de suas terras e bens assim melhor disponibilizados ao sucesso do empreendimento.

\section{Conflitos ambientais no Brasil entre os anos 1980 e 2000}

Segundo Acselrad (2004), podemos reconhecer dois momentos diferentes de emergência dos conflitos ambientais no Brasil. Em um primeiro momento, até os anos 1980, grandes projetos de apropriação do espaço foram implementados pelo Estado brasileiro "desenvolvimentista", articulando-se com a implantação de uma complexa estrutura industrial espacialmente concentrada, ocorrendo assim a ampliação dos espaços integrados à dinâmica do desenvolvimento capitalista. Aceleraram-se os ritmos do ciclo industrial de extração de materiais, emissão de efluentes e resíduos, ancorados na 
concentração da renda e nas exportações (ACSELRAD, 2004). Isso tudo causou grande desestruturação nos ecossistemas, deslocando populações que dependiam dessa base de recursos para áreas menores e menos férteis, levando à intensificação desse uso e comprometendo, com o tempo, sua qualidade. Os conflitos ambientais foram então se avolumando. Com a maior abertura democrática nos anos 1980, muitas práticas sociais perseguidas e silenciadas ao longo de duas décadas foram se fortalecendo: novas vozes se expressam, projetos alternativos conquistam (e criam) um espaço público de debate, inovações administrativas são gestadas no governo, movimentos sociais começam a ser reconhecidos em suas lutas por direitos e em suas propostas alternativas de sociedade, os impactos negativos do modelo de desenvolvimento socioeconômico - antes ocultados puderam vir à tona.

6 Em um segundo momento, nos anos 1990 acelerou-se a inserção brasileira no mercado capitalista mundializado através da especialização de funções de diferentes porções do território nacional, intensificando a corrida pela captação de investimentos internacionais.

7 Nesse modelo a "natureza" foi concebida ou como estoque de valor para esse mercado (natureza a ser conservada), ou como campo de expansão de empreendimentos incompatíveis com sua conservação (natureza a ser destruída). Para tanto se promoveu a flexibilização das normas ambientais e a fragilização das agências públicas responsáveis pela aplicação delas. Contra essa intensa "desregulação do ambiente" é que emerge um novo momento dos conflitos ambientais no Brasil. Nesse sentido, tanto o que é valorizado pela proximidade da "natureza a ser conservada" quanto o que é desvalorizado pela proximidade da "natureza a ser destruída" constituem-se forças de expulsão-exclusão de populações de menor renda e menor poder político para se expressarem nas arenas públicas, fazendo valer seus direitos. No primeiro caso podemos encontrar tudo o que ganha valor de mercado ou tem seu preço aumentado, tornando-se inacessível ou inviável para tais populações; e no segundo, encontramos tudo o que, perdendo seu valor de troca e de uso implica na degradação da saúde, na elevação não apenas dos riscos, mas também da efetiva contaminação e óbitos resultantes de degradação do ambiente em que vivem essas populações. Vemos aí a pressão social para a permanência desses grupos sociais mais vulneráveis nas proximidades das zonas industriais, abandonadas ou não, dos botaforas e lixões - contexto bem representado nas denúncias de racismo ambiental nos EUA nos anos 1980.

Conceitualmente, os conflitos ambientais se originam quando a forma de sobrevivência de alguns grupos sociais no território é ameaçada por impactos indesejáveis - transmitidos pelo solo, água, ar ou sistemas vivos -, causados pela ação de outros grupos sociais (ACSELRAD, 2004). Estes conflitos vêm a público a partir da ação de denúncia dessas atividades indesejáveis, mas a configuração dos conflitos acontece mesmo é durante as ações de disputa entre os atores sociais, quando fica explícito que a distribuição de poder entre eles e o respeito aos direitos de cada um é muito desigual, motivo que faz com que as populações afetadas contestem e até se revoltem contra essa "realidade". Passa a existir assim uma disputa por recursos, que não são apenas materiais, mas também simbólicos.

9 São simbólicos por envolver o desafio de se conquistar espaços de expressão das insatisfações e injustiças, de comunicação com a opinião pública pela mídia, de cobrança da legislação e influência na elaboração de novas leis, de luta por reconhecimento de legitimidade e de identidades. 
10 Uma grande contribuição da dinâmica dos conflitos ambientais é justamente sua saída da invisibilidade histórica para alcançar o debate público, reclamando a democratização das decisões sobre a produção socioespacial dos territórios, problematizando os consensos que nos são empurrados diariamente - tal como o consenso do desenvolvimento (dito) sustentável. Vale lembrar que o ideário da "sustentabilidade", polemicamente consagrado na Rio-92, desde então tem sido cooptado como importante combustível da renovação da própria lógica capitalista.

\section{Justiça ambiental}

11 Acselrad (2004) indica a abordagem da justiça ambiental como a mais coerente para enfrentarmos a questão dos conflitos ambientais, evitando tratá-los apenas em termos de eficácia e eficiência na mediação entre interesses, típico de abordagens tecnocráticas e economicistas. Nesse mesmo sentido, ele critica as chamadas tecnologias de consenso (imbricadas à engenharia de favorecimento dos negócios), que desqualificam as reivindicações dos demandantes e restringem as "soluções" da questão a benefícios particulares, negociados sob persuasão e coerção.

12 A relevante produção de conhecimento sobre o campo dos conflitos ambientais tem revelado que a maior carga dos danos ambientais do desenvolvimento é destinada prioritariamente às populações de baixa renda, aos grupos sociais discriminados, aos povos étnicos tradicionais, aos bairros operários, às populações marginalizadas e vulneráveis: a injustiça ambiental é o mecanismo que viabiliza e realiza isso tudo (ACSELRAD, 2004; ACSELRAD, HERCULANO e PÁDUA, 2004; LEROY \& ACSELRAD, 2006; ZHOURI; LASCHEFSKI e PEREIRA, 2005; ZHOURI, LASCHEFSKI, 2010).

Pensar esse quadro em termos de justiça ambiental significa entender que os efeitos da degradação ambiental são desigualmente distribuídos entre a população (ao contrário do que se costuma dizer sobre as questões ambientais), dependendo de seu poder econômico e político de influenciar opinião e decisões públicas. Ao criticar a concentração dos riscos ambientais sobre as populações mais enfraquecidas, estaríamos então combatendo a degradação ambiental de um modo geral, uma vez que os impactos negativos não mais poderiam ser transferidos para os mais pobres.

\section{Sobre desregulação, desenvolvimento local e política de escalas}

Acselrad (2002) denuncia a receita que tem guiado a dinamização das economias local, regional ou nacional, na chamada nova ordem mundial competitiva (globalização), nomeando-a de desregulação institucional. Isso se daria no contexto de novas formas de organização que pretender transcender o sistema dos Estados-Nação, desterritorializando e reterritorializando capitais, produzindo tensões e conflitos sociais na medida em que pretende destituir tais processos das "referências às relações de poder que aí se encontram" (ACSELRAD, 2002, p.33). Segundo o autor, essa reestruturação das geografias da circulação e da acumulação do capital altera as escalas de governo existentes, onde os capitais financeiros tornam-se independentes das estruturas produtivas e da regulação dos Estados, e os Estados nacionais continuam fortes reguladores da fixação espacial da força de trabalho. Segundo Acselrad (2002, p.34) "substituiu-se a política operada em 
escalas abrangentes pelos procedimentos técnicos acionados em escalas locais e fragmentárias", e nos Estados Nacionais periféricos, como o Brasil, estreitaram-se os espaços de possibilidade para o exercício das políticas públicas, ajustes que seguem a cartilha do "Consenso de Washington":

Pois o que um certo discurso hegemônico vem pretendendo induzir é que os processos históricos passem a ser substancialmente governados pela própria dinâmica da inovação tecnológica, em detrimento das escolhas coletivas fundadas em valores e projetos que podem ser debatidos no espaço público (ACSELRAD, 2002, p.34)

O autor diz ainda que, uma vez sendo eleita a capacidade de inserção internacional como o principal fator de dinamização econômica, o discurso da necessidade de competição legitimou o desemprego. 0 planejamento estatal agora considera que é a própria crise o "motor do desenvolvimento". Esse cenário é interpretado pelo autor como um resultado histórico que envolveu a transformação da noção de governo do território (na prémodernidade) para a de governo de homens e coisas, onde ele localiza a emergência da Economia Política, associada a uma Biopolítica que precisava fornecer o recurso trabalho à nascente produção capitalista. Entre os indícios desse movimento ele aponta as privatizações e os discursos sobre "parcerias", "responsabilidade social das empresas" e de uma "sociedade que toma nas mãos os seus próprios problemas" (ACSELRAD, 2002, p.36).

A manutenção dessa nova ordem seria fundamental para os fluxos de capitais mundializados, restringindo - conforme deseja o Banco Mundial - os formatos governativos para que melhor se defendam da "explosão de demandas sociais e corporativas", concentrando o poder decisório. Em resumo, a boa governança tem significado (para países como o Brasil que seguem o "receituário liberal") a abdicação da responsabilidade do Estado para com as políticas sociais, com a educação e o meio ambiente: "subordinou a saúde da população à saúde dos bancos e a sustentabilidade do meio ambiente à sustentabilidade dos fluxos financeiros especulativos" (ACSELRAD, 2002, p.37). Essa boa governança tende, portanto, a invisibilizar os mais pobres, coagindo-os para que não onerem todo esse sistema. Ou como diz Jacques Rancière, nessa nova ordem é preciso impedir que os "não-considerados" apareçam na cena pública como divergência ou reivindicação, impedi-los da tentativa de representar a si mesmos (RANCIÈRE, 1996). Para Rancière (com quem Acselrad também dialoga), a Política deve ser entendida como a atividade que tem por racionalidade própria a racionalidade do desentendimento. Assim também entende Marilena Chauí: a democracia seria o único regime político onde os conflitos sociais são considerados o próprio princípio de seu funcionamento; impedi-los de se expressar seria destruir a própria democracia (FOLHA DE SÃO PAULO, 2003). Mas na atual ordem social estaríamos mais próximos de uma Polícia que de uma Política, como diz Rancière. $O$ conceito de Política trabalhado por este autor traz como princípio a igualdade, uma igualdade que não está lá longe como um sonho que será alcançado talvez um dia, mas sim uma potencialidade que só ganha realidade se é atualizada no aqui e agora. E essa atualização se dá por ações que irão construir a possibilidade dos "não-contados" serem levados em conta, serem considerados nesse princípio básico e radical de igualdade.

Citado por Chico de Oliveira, diz Rancière que a Política é a reivindicação da parte daqueles que não têm parte; que política se faz reivindicando "o que não é nosso" pelo sistema de direitos dominantes, criando assim um campo de contestação (OLIVEIRA, 2004). $O$ autor acredita que em uma sociedade como a nossa em que os que não têm parte 
são a maior parte, é preciso fazer Política. Rancière chama de dano a não-realização dessa suposta igualdade; a reivindicação desses que não "cabem" na sociedade mas estão nela, coloca em destaque que está ocorrendo o dano: a contagem oficial da população - a Biopolítica que fala Acselrad - não dá conta dessa população. Mas seria precisamente quando essas duas ordens de definição entram em oposição (explicitando o desentendimento) que aconteceria a Política. Na atual "pós-democracia consensual" (Rancière apud ACSELRAD, 2002, p.38) condena-se o conflito e considera-se razoável apenas a sua resolução ótima baseada no conhecimento do que é possível e na discussão entre "parceiros" legitimados socialmente. A prática consensual é assim, a prática do apagamento das formas do agir democrático e, por isso, para Rancière, democracia e consenso são termos contraditórios: o consenso seria o desaparecimento da política. Frustrando as expectativas da abertura democrática brasileira nos anos 1980, diz Acselrad (2002) que o paradigma vigente hoje é o da "desqualificação da política", o que viria justificando o deslocamento de "temas antes políticos" para a esfera privada:

"Políticas governamentais são transferidas para atores não-estatais através de novos canais como fóruns, conselhos, Agendas 21 locais, que se pretendem alheios aos males da política, pequena esfera a ser deixada doravante ao arbítrio das elites "por sua pouca relevância e eficácia". As instituições privadas da sociedade civil passam a encarar a unidade, antes prerrogativa da autoridade política estatal. Os valores, modelos culturais e regras do jogo em que se definem os interesses são considerados indiscutíves e os interesses diversos são simbolicamente unificados. Economiza-se por fim a política, através de metáforas econômicas da "cidadeempresa" para as políticas urbanas, [...] da atribuição de preços aos elementos não-mercantis do meio ambiente, da consideração da capacidade de venda como expressão do valor do conhecimento produzido nas Universidades etc" (ACSELRAD, 2002, p.38)

O autor cita o caso dos Conselhos Municipais, cada vez mais participativos em sua composição, mas menos decisórios em sua pauta e "mais passíveis de apropriação por uma política-espetáculo", uma democracia imagética (ACSELRAD, 2002, p.38). Se por um lado, como diz o autor, tal cenário é influenciado pelos discursos de busca de consenso social, segurança e sustentabilidade ecológica, por outro, estaria cada vez mais difícil de se invisibilizar a ruptura dos laços de sociabilidade, a segregação socioespacial e a violência social. Cria-se assim um "vazio político" que se tentará preencher - em vão - pela promoção da "cidadania local" e dos "laços comunitários", elementos de uma "democracia de proximidade" oferecida como remédio à desagregação social; mas "as causas mais profundas da exclusão não podem ser encontradas na esfera local”, fazendose do local uma expressão da razão "globalitária" (ACSELRAD, 2002, p.39). A partir dos anos 1980 teria havido uma aposta no dinamismo local para que se revertessem os aspectos negativos das políticas de desenvolvimento "de cima para baixo", consagrando-se aí a noção de desenvolvimento local: "O desenvolvimento local liga-se assim, intimamente a uma abordagem pragmática, traduzida na realização de projetos concretos, que levem em conta as especificidades do território e o enraizamento dos atores - as chamadas sinergias locais"”. (ACSELRAD, 2002, p.40)

Distanciando-se do que poderia ser uma visão determinista e fatalista, Acselrad aponta também o caráter paradoxal e contraditório do desenvolvimento local, onde os movimentos sociais disputam com as elites - empresariais e políticas - a atribuição de significados: os primeiros reivindicam "o aumento da democracia local e a integração do conjunto da população"; e os últimos "enfatizam a competição internacional, o foco em setores de ponta e o aumento das vantagens comparativas da cidade na rede hierarquizada de 
cidades e competição" (ACSELRAD, 2002, p.41). O que os governos locais buscam, diz o autor, são formas de coalizão - "especialmente com o poder empresarial" - para angariar recursos não-governamentais, para enfrentar a fragmentação de poderes econômicos e políticos.

Acselrad diz que as parcerias locais surgidas nos anos 1990 eram na verdade motivadas pela disputa de recursos, sendo melhor compreendidas no contexto da "distribuição de fundos do governo central mediante programas que enfatizam a competição interlocal", ao contrário do discurso de "atribuição de poder às comunidades" e de favorecimento de sua autonomia (ACSELRAD, 2002, p.42).

21 Encontramos em Harriss (2001) uma crítica à noção de capital social, associada a este mesmo campo semântico e ideológico do desenvolvimento local, da ativação das sinergias locais. Segundo o autor, o entusiasmo com a perspectiva de construção de capital social alinha-se com agenda neo-liberal de redução do papel do Estado e das despesas públicas, descontextualizando a questão do desenvolvimento das relações de poder na sociedade (HARRISS, 2001, p.30). Assim:

«[...] essa nova ênfase no desenvolvimento da comunidade estaria ligada ao objetivo neoliberal mais amplo de criar cidadãos ativos para promover o apoio mútuo e a iniciativa local, e reduzir a "dependência" dos atores locais em relação ao Estado de Bem-Estar Social. Esse tipo de parceria, estabelecido com o objetivo de competir por fundos governamentais, acabaria, ao contrário dos propósitos explícitos que a justificam, por restringir a autonomia dos atores locais no processo de definição das estratégias de regeneração do local ». (ACSELRAD, 2002, p.42)

Na medida em que os poderes e recursos efetivos das comunidades não acompanharem os discursos oficiais de "igualdade entre os parceiros", o envolvimento delas nas estratégias de desenvolvimento local poderá assumir duas principais funções nesse cenário, diz o autor: legitimar programas públicos ou oferecer "bodes expiatórios" para eventuais fracassos das políticas públicas no local (ACSELRAD, 2002, p.42). Diz ainda Acselrad que, acionando uma "lógica exógena" o desenvolvimento local significa a busca de funções especializadas para regiões, cidades ou localidades em novos circuitos integradores, em troca de alguns benefícios que se estendem à sociedade. E acionando uma "lógica endógena", ele fomentaria uma organização socioeconômica alternativa em busca da ativação e melhor aproveitamento de recursos próprios - "práticas potencialmente inovadoras, poupança local, ofertas de emprego correspondentes às novas aspirações coletivas quanto à qualidade de vida, meio ambiente, lazer, etc" (ACSELRAD, 2002, p.42). Mas considerar que "a crise vem do alto" (é global) e que "a solução vem de baixo" (é local), opondo endógeno a exógeno, seria apenas uma estratégia persuasiva, pois ambas estão relacionadas e o poder de disposição sobre os recursos materiais e institucionais não se situa nem no local nem no global, mas "naqueles atores dotados de maior mobilidade espacial e de maior capacidade de efetuar o que se entende crescentemente ser uma política de escalas" (ACSELRAD, 2002, p.43).

\section{Democracia é conflito}

Marilena Chauí diz que, para a classe dominante brasileira (os "liberais"), democracia é o regime da lei e da ordem. Para ela, no entanto, a democracia é "o único regime político no qual os conflitos são considerados o princípio mesmo de seu funcionamento": impedir a expressão dos conflitos sociais seria destruir a democracia (FOLHA DE SÃO PAULO, 2003). 
O filósofo Jacques Rancière critica a idéia de democracia que tem estruturado nossa vida social (regida por uma ordem policial, segundo ele) por ela se distanciar do que seria sua razão de ser: a instituição da política (RANCIÈRE, 1996). Estamos acomodados a acreditar que a política é isso que está aí: variadas formas de acordo social a partir das disputas entre interesses, resolvidas por um conjunto de ações e normas institucionais. Essa ideia empobrecida do que seja a política está, para o autor, mais próxima da idéia de polícia, já que diz respeito ao controle e vigilância dos comportamentos humanos e sua distribuição nas diferentes porções do território, cumprindo funções consideradas mais ou menos adequadas à ordem vigente. Estamos geralmente tão hipnotizados pela "necessidade de um compromisso para se alcançar o bem-comum" e pela opinião geral de que "as instituições sociais já estão fazendo todo o possível para isso", que não conseguimos perceber nossa contribuição na legitimação dessa política policial que administra alguns corpos e torna invisíveis outros.

O conceito de Política trabalhado pelo autor traz como princípio a igualdade, uma igualdade que não está lá como sonho a ser alcançado um dia, mas que é uma potencialidade que só ganha realidade se é atualizada no aqui e agora. E essa atualização se dá por ações que irão construir a possibilidade dos "não-contados" serem levados em conta, serem considerados nesse princípio básico e radical de igualdade. Para além dos movimentos sociais, existem os ainda-sem-nome e ainda-sem-movimento. Diz o autor que a Política é a reivindicação da parte daqueles que não têm parte; política se faz reivindicando "o que não é nosso" pelo sistema de direitos dominantes, criando assim um campo de contestação. Como diz Chico de Oliveira, em uma sociedade em que os que não têm parte são a maior parte, é preciso fazer Política (OLIVEIRA, 2004). Para Rancière, a Política é a atividade que tem por racionalidade própria a racionalidade do desentendimento . Mas vivemos sob uma ordem social hegemônica (marcada pela força do compromisso entre Mercado, Direito, Estado e Mídia), uma ordem "que define as divisões entre os modos de fazer, de ser e de dizer dos corpos" (a tal polícia que fala Rancière). 0 discurso da igualdade que essa ordem promete (por exemplo na imagem de um Estado de direito) não é a mesma igualdade concebida pelo autor como princípio da política. Essa segunda definição de igualdade é a que é reivindicada por uma outra ordem de práticas, que criam transgressões na ordem hegemônica (quando, e se conseguem). $\mathrm{O}$ autor chama de dano a não-realização dessa suposta igualdade. A reivindicação desses que não "cabem" na sociedade mas estão nela, coloca em destaque que está ocorrendo o dano: a contagem oficial da população não dá conta dessa população. É quando essas duas ordens de definição entram em oposição (explicitando o desentendimento) que acontece a política. Mas essa oposição encontra forças poderosas de repressão e controle, marcadas pela pressão para o consenso. Nessa democracia consensual condena-se o conflito e considera-se razoável apenas a sua resolução ótima baseada no conhecimento do que é possível e na discussão entre "parceiros" legitimados socialmente. A prática consensual é assim, a prática do apagamento das formas do agir democrático. Não é permitido estar fora desse consenso, e só se garantiria alguma igualdade obedecendo a ordem política policial de "ser igual aos iguais".

Por isso, para o autor, democracia e consenso são termos contraditórios: o consenso é o desaparecimento da política. Pelas estratégias de controle e formação da opinião pública, o povo precisa continuamente receber uma imagem pré-fabricada de si mesmo e da organização social (tipo "Estado de direito"), manipulando os "não-considerados" para 
que não apareçam na cena pública como divergência ou reivindicação, nem tentem representar a si mesmos.

Se desconsiderarmos as condições sociais em que tal consenso é produzido, as forças políticas policiais ficam invisíveis e, assim também, toda a violência dos consensos forçados. Como no caso em que o conflito em si é considerado um problema a ser resolvido, um defeito do sistema harmônico a ser identificado e conduzido por peritos até o regime do "possível de ser feito" pelo Estado. Se não for "possível”, esse "problema" não é considerado razoável e novamente se reforça a legitimidade e necessidade de uma política policial, repressora. Apagando esse tipo de conflito que potencialmente surge de um "povo esquecido na contagem", fica fácil sugerir a harmonia entre um Estado gestor (aquele que administra) e um Estado de direito.

\section{A representação dos "não-considerados": novas cartografias sociais}

Em meio à "política das escalas" desempenhada pelos atores hegemônicos e a luta por direitos daqueles que sofrem danos em função de tais ações, vemos emergir as disputas pela afirmação territorial destes últimos, favorecidos pela diversidade de estratégias de mapeamentos participativos que vem ocorrendo no Brasil nos últimos vinte anos. Nesses mapeamentos a proposta é a inclusão de populações locais nos processos de produção de mapas, quando historicamente estiveram envolvidas diferentes instituições, principalmente: agências governamentais, ONGs, organizações indígenas, organismos multilaterais e de cooperação internacional, fundações privadas e universidades (ACSELRAD e COLI, 2008).

Se os mapeamentos participativos outrora carregavam principalmente os objetivos das agências promotoras do desenvolvimento, hoje podemos ver o destaque de sua contribuição pendendo para a chamada "guerra dos mapas":

“(...) se por um lado, tornam-se claras as implicações políticas dos mapas, podemos falar, por outro lado, da emergência de políticas cartográficas, em que os mapeamentos são eles próprios objeto da ação política. E se ação política diz especificamente respeito à divisão do mundo social, podemos considerar que na política dos mapeamentos estabelece-se uma disputa entre distintas representações do espaço, ou seja, uma disputa cartográfica que articula-se às próprias disputas territoriais" (ACSELRAD e COLI, 2008, p.14).

Entre essas estratégias destaco aqui o projeto Nova Cartografia Social da Amazônia, coordenado pelo antropólogo Alfredo Wagner Berno de Almeida, que tem como objetivo "dar ensejo à auto-cartografia dos povos e comunidades tradicionais na Amazônia". 0 interesse do projeto não é apenas obter um maior conhecimento sobre o processo de ocupação da Amazônia "mas sobretudo uma maior ênfase e um novo instrumento para o fortalecimento dos movimentos sociais que nela existem" (PROJETO NOVA CARTOGRAFIA SOCIAL DA AMAZÔNIA, 2011). Tais movimentos sociais consistem em manifestações de identidades coletivas, referidas às situações sociais peculiares e territorializadas. Estas territorialidades específicas, construídas socialmente pelos diversos agentes sociais, é que suportam as identidades coletivas objetivadas em movimentos sociais. A força deste processo de territorialização diferenciada constitui o objeto deste projeto, apontam seus coordenadores. 
O projeto, que hoje já conta com um grande número de fascículos representativos das pesquisas em auto-cartografias realizadas em muitas regiões do Brasil traz uma forte perspectiva prática e de apoio ao fortalecimento dos movimentos sociais, além de o fazer a partir de suas expressões culturais diversas: "A cartografia se mostra como um elemento de combate. A sua produção é um dos momentos possíveis para a autoafirmação social". Sobre a metodologia do Projeto, como dizem seus coordenadores:

“(...) cada fascículo é resultado de uma relação social específica entre um povo ou comunidade tradicional e a equipe de pesquisadores. É o movimento social que busca o PNSCA para realizar a cartografia. A partir desse interesse manifesto, é realizada uma oficina de mapas com a participação de cerca de 30 agentes sociais e os pesquisadores membros do Projeto. Nela, os pesquisadores ensinam técnicas de GPS e de mapeamento, além de conversar com os agentes e coletar depoimentos sobre a história social e problemas da comunidade. Os agentes sociais produzem croquis, mapeando sua região e indicando quais os elementos relevantes para a sua composição. Em um segundo momento, sem a presença dos pesquisadores, os agentes sociais marcam, com GPS, os pontos do que consideram significativo de seu território. Na seqüência, o PNSCA recolhe as informações das marcações de ponto e as georeferencia na base cartográfica, inserindo as ilustrações produzidas nos croquis. Essas ilustrações compreendem desenhos, esboços e reproduções de símbolos e objetos (remos, casas, embarcações, instrumentos de trabalho, animais, plantas, etc.) que são transformados, a partir do trabalho da equipe de pesquisadores, em ícones para compor as legendas dos mapas. Simultaneamente, transcreve-se excertos de depoimentos e seleciona-se os que comporão o fascículo." (PROJETO NOVA CARTOGRAFIA SOCIAL DA AMAZONIA, 2011)

31 Ainda de acordo com informações disponibilizadas no site do Projeto, após publicados os fascículos, a maior parte dos exemplares fica de posse do movimento social, podendo utilizá-los como parte integrante de sua estratégia de auto-afirmação social e de resolução de seus problemas. A consolidação deste projeto acontece desde as experiências de mapeamento social realizadas na área correspondente ao "Programa Grande Carajás", em 1991-93, e na região ecológica de babaçuais, em 2005, dizem os coordenadores. Entre os movimentos sociais abrangidos pelo Projeto poderíamos citar as Quebradeiras de Coco Babaçu dos Estados do Piauí, Maranhão e Pará; as Comunidades Quilombolas dos Estados do Pará, Maranhão, e Amazonas; artesãos e artesãs, ribeirinhos, ribeirinhas, piaçabeiros e peconheiros dos Estados do Amazonas e Pará; os povos dos Faxinais, dos Fundos de Pasto, Pescadores, Ribeirinhos, Cipozeiros e Povoado Pantaneiro, nos Estados do Paraná, Bahia, Pará, Amazonas, Roraima, Pernambuco, Espírito Santo, Santa Catarina e Mato Grosso. A partir de 2006 o Projeto estendeu suas pesquisas aos Conflitos nas Cidades da Amazônia, alcançando já hoje dez trabalhos realizados na cidade de Belém, além de nove trabalhos na cidade de Manaus. Em Belém as pesquisas envolveram Indígenas, Homossexuais, Afroreligiosos, Negras e Negros, Catadores, Pessoas com deficiências, Feirantes e Ribeirinhos.

\section{Conclusões provisórias}

A compreensão da dinâmica social como essencialmente conflitual (e por isso mesmo não patológica, nem a ser "sanada") traz em destaque a importância da dimensão política, da democratização, para os processos de produção do espaço geográfico. A segunda onda dos conflitos ambientais que se destacam no Brasil a partir dos anos 1990 é marcada por processos de desregulação do ambiente, justamente quando a dinâmica da globalização cobra que se retire a natureza dos conflitos sociais, facilitando a disponibilização do 
ambiente para as especializações exigidas do território, pelo capital: seja para a degradação seja para a conservação, com seus processos de desvalorização e valorização. Os sujeitos coletivos desenvolvem variadas formas de resistência à ação de projetos representantes das dinâmicas hegemônicos de reprodução do capital, resistência à mercantilização da vida, integrada a formas de resistência territorial. E embora tenham geralmente prejudicadas suasvariadas formas de existência cultural, social e política, vêm conquistando novos recursos simbólicos relevantes para a disputa pela legitimação de sua existência, e deslegitimação do caráter policial das políticas desenvolvimentistas. Destacam-se aí o campo dos estudos dos conflitos ambientais, a corrente da justiça ambiental e a abordagem das cartografias sociais que colaboram para o fortalecimento dos movimentos sociais e para a democratização da produção sócio-espacial.

\section{BIBLIOGRAPHY}

ACSELRAD, Henri Território e poder: a política das escalas. In: FISCHER, T. (org). Gestão do desenvolvimento e poderes locais: marcos teóricos e avaliação. Salvador: Casa da Qualidade, 2002.

. As práticas espaciais e o campo dos conflitos ambientais. In: ACSELRAD, H. (org). Conflitos Ambientais no Brasil. Rio de Janeiro: Relume/Dumará: Fundação Heinrich Böll, 2004.

. Editorial. Revista Rio de Janeiro, n. 16-17, maio-dez. 2005, pp. 7-10. Editada pela UERJ/ OUERJ/Fórum-Rio.

. Conflito social e meio ambiente no Estado do Rio de Janeiro. Rio de Janeiro: Relume Dumará/ FASE, 2004.

, COLI, L. R. Disputas territoriais e disputas cartográficas. In: ACSELRAD, H. (Org). Cartografias Sociais e Território. Rio de Janeiro: UFRJ/IPPUR, 2008.

, HERCULANO, S., PÁDUA, J.A. (orgs). Justiça Ambiental e Cidadania. Rio de Janeiro: Relume Dumará/Fundação Ford, 2004.

FOLHA DE SÃO PAULO. Democracia é conflito, não ordem, diz Chauí. Jornal Folha de São Paulo, 03/08/2003.

HARRISS, J. Public action and the dialectics of decentralisation: against the myth of social capital as "the missing link in development". Social Scientist, vol. 29, n.11/12., pp. 25-40, nov-dec, 2001.

EROY, Jean Pierre, ACSELRAD, Henri (Coords.). Mapa dos conflitos ambientais no Estado do Rio de Janeiro (CD-ROM). Rio de Janeiro: FASE/BSD \& ETTERN/IPPUR/UFRJ, 2006.

OLIVEIRA, F. Por quê política? Documento do Fórum da Sociedade Civil na Unctad, em São Paulo, 14, 15 e 16 de junho de 2004. Ibase/ActionAid Brasil/Attac Brasil e Fundação Rosa Luxemburg. Disponível em: www.ibase.br/userimages/francisco_de_oliveira_port.pdf.

PROJETO NOVA CARTOGRAFIA SOCIAL DA AMAZÔNIA. Apresentação. Acesso em 20/09/2011. Disponível em http://www.novacartografiasocial.com/. 
REPORTAGEM INTER TV/REDE GLOBO. Audiência Pública discute a implantação do distrito industrial em São João da Barra. Postada em 02/09/2011a. Disponível em: http://www.youtube.com/watch? $\mathrm{v}=\mathrm{M} 60 \mathrm{mFKU} 4 \mathrm{~F} 9 \mathrm{M}$.

REPORTAGEM INTER TV/REDE GLOBO. Familias do 5ํㅓㄴ ditrito de São João da Barra começam a ser reassentadas. Postada em 14/09/2011b. Disponível em:

http://www.youtube.com/watch?v=xvm9Ble2C90\&feature=related.

RANCIÈRE, J. O desentendimento: política e filosofia. São Paulo: Editora 34, 1996.

SOFFIATI NETTO, A. A. Diálogo leal sobre o Açu (II). Folha da Manhã, Campos dos Goytacazes (RJ), 10 de julho de 2011.

ZHOURI, A., LASCHEFSKI, K., PEREIRA, D.B. (orgs). A insustentável leveza da política ambiental: desenvolvimento e conflitos socioambientais. Belo Horizonte: Autêntica, 2005.

ZHOURI, A., LASCHEFSKI, K. (Orgs). Desenvolvimento e conflitos ambientais. Belo Horizonte: Editora UFMG, 2010.

\section{ABSTRACTS}

Este artigo busca enfatizar a relevância teórica e os impactos empíricos da corrente denominada Justiça Ambiental e do projeto intitulado Novas Cartografias Sociais, situando a valorização da natureza no centro de conflitos históricos, políticos e sociais.

This article emphasizes the theoretical relevance and the empirical impacts from the Environmental Justice and the New Social Cartographies Project, placing the appreciation of nature in the heart of historical, political and social conflicts.

Cet article veut signaler l'importance théorique et les conséquences empiriques du courant de pensée intitulé Justice Environnementale, ainsi que du projet appelé Nouvelles Cartographies Sociales. Ils se distinguent pour situer la valorisation de la nature au centre de conflits historiques, politiques et sociaux.

\section{INDEX}

Palavras-chave: justiça ambiental, conflitos ambientais, novas cartografias sociais, política, Brasil

Keywords: environmental conflicts, environmental justice, politics, Brazil

Mots-clés: conflits environnementaux, nouvelles cartographies sociales, politique, Brésil

\section{AUTHOR}

\section{MARCO ANTONIO SAMPAIO MALAGODI}

Doutor em Psicologia Social pela USP (Universidade de São Paulo) e Professor Adjunto no Curso de Geografia da UFF (Universidade Federal Fluminense) - Pólo Universitário de Campos dos Goytacazes (RJ). E-mail: marcomalagodi@id.uff.br 